\title{
Learning-based dynamic capabilities in closed-loop supply chains: an expert study
}

\author{
Ilkka Ritola, Harold Krikke and Marjolein C.J. Caniëls \\ Open Universiteit, Heerlen, The Netherlands
}

\begin{abstract}
Purpose - Product returns information gives firms an opportunity for continuous strategic adaptation by allowing them to understand the reasons for product returns, learning from them and improving their products and processes accordingly. By applying the Dynamic Capabilities (DCs) view in the context of closed-loop supply chains (CLSC), this study explores how firms can continuously learn from product returns information. Design/methodology/approach - This study adopts a qualitative Delphi study-inspired approach. Experts from industry and academia are interviewed in two interview rounds. First round of interviews are based on extant research, while the second round allows the experts to elaborate and correct the results.

Findings - This study culminates into a conceptual model for incremental learning from product returns information. The results indicate incremental learning from product returns can potentially lead to a competitive advantage. Additionally, the authors identify the sources of information, capabilities along with their microfoundations and the manifestations of product return information. Three propositions are formulated embedding the findings in DC theory.

Research limitations/implications - This study supports extant literature in confirming the value of product returns information and opens concrete avenues for research by providing several propositions.

Practical implications - This research elucidates the practices, processes and resources required for firms to utilize product returns information for continuous strategic adaptation. Practitioners can use these results while implementing continuous learning practices in their organizations.

Originality/value - This study presents the first systematic framework for incremental learning from product returns information. The authors apply the DC framework to a new functional domain, namely CLSC management and product returns management. Furthermore, the authors offer a concrete example of how organizational learning and DC intersect, thus advancing DC theoretical knowledge.
\end{abstract}

Keywords Closed-loop supply chain, Circular economy, Reverse logistics, Product returns, Organizational learning, Knowledge management, Information systems, Innovation, Dynamic capabilities

Paper type Research paper

\section{Introduction}

Closed-loop supply chain (CLSC) management has been receiving increasing attention by both researchers and practitioners during recent years. The increased attention can be partly explained by the increased demand for sustainable business practices by consumers and regulations but also, to a large extent, by the value creation opportunities that CLSC presents for enterprising firms (Schenkel et al., 2015, 2019; Krikke et al., 2013; Koppius et al., 2014; Jayaraman and Luo, 2007). Importantly, CLSC value creation is not geared for short-term profit optimization. Instead, researchers have identified four types of values that firms can generate long term from CLSC activities (Krikke et al., 2013; Koppius et al., 2014; Schenkel et al., 2015): economic value, customer value, environmental value and informational value. This study focuses on the least understood (Krikke et al., 2013; Schenkel et al., 2015), and yet

(C) Ilkka Ritola, Harold Krikke and Marjolein C.J. Caniëls. Published by Emerald Publishing Limited. This article is published under the Creative Commons Attribution (CC BY 4.0) licence. Anyone may reproduce, distribute, translate and create derivative works of this article (for both commercial and noncommercial purposes), subject to full attribution to the original publication and authors. The full terms of this licence may be seen at http://creativecommons.org/licences/by/4.0/legalcode.

Received 25 January 2021 Revised 30 May 2021 17 August 2021

Accepted 22 August 2021

\section{Learning- capabilities}


IJLM

33,5

70

highly significant (Jayaraman and Luo, 2007; Röllecke et al., 2018), type of CLSC value creation: the informational value.

Informational CLSC value is a broad concept encompassing information from product inspections, customer feedback and data from the product return process (Ritola et al., 2020). It can be used to improve processes, products, strategic change and innovation. In short, by systematically learning from product returns information, firms generate the other three types of CLSC value. Scholars have examined CLSC value creation from many vantage points, including resource-based view (Daugherty et al., 2002, 2005; Jayaraman and Luo, 2007), organizational knowledge creation theory (Mihi-Ramirez, 2012; Mihi-Ramírez and Morales, 2011), game theory (Heese et al., 2005), transaction cost economics (Martin et al., 2010) and stakeholder theory (Schenkel et al., 2015). Informational value stems from customer contact that is always context-specific and based upon the reason for the return that bears importance on specific processes, products, policies and other organizational resources during a specific time.

It has long been argued that an essential source of learning comes from customers who use the product (Rosenberg, 1982; Fundin and Bergman, 2003; Fundin and Elg, 2010). As product returns information opens a window into customer behavior, we postulate that CLSC informational value is a source for continuous organizational learning. Further, we argue that systematic learning and application from this information is an instance of a dynamic capability (DC). The DC view aims at understanding competitive advantage in dynamic market environments (Teece, 2007) by maintaining and restoring fit with changing customer requirements (Mahringer and Renzl, 2018). Scholars have identified DCs in the context of supply chain management (Blome et al., 2013) and sustainable supply chain management (Beske, 2012; Beske et al., 2014). Extending this line of research into the domain of CLSC management, we argue that by continuously learning from product returns information, firms can better understand the needs of their customers thus better meeting their needs, ultimate leading to competitive advantage.

This exploratory research aims to develop a framework for incremental organizational learning from product returns by integrating organizational learning practices and CLSC practices under the DC framework. More specifically, this study conceptualizes product returns information as a source for continuous incremental learning and explores its viability from the DC perspective. Considering the novelty of this topic, both in practice and in research, we undertake an exploratory Delphi study using interviews.

This study is the first one that applies the DC framework to CLSC management and the informational value of product returns. It contributes to practice by providing a conceptual framework, agreed upon by practitioners and academic experts, that assists business practitioners in building the necessary capabilities needed for their specific business needs. The theoretical contribution lies in combining organizational learning theory with the DC framework. This study clarifies the different types of information available from product returns. Furthermore, it answers to the call to apply the DC framework to new functional domains (Schilke et al.,2018), by exploring the role of DC in the domain of CLSC management and product returns information. By analyzing product returns information and providing insights into how other kinds of values can be generated from it, this study also contributes to knowledge value chain research (Gaimon and Ramachandran, 2020) and in increased knowledge regarding the enablers and barriers to learning processes, feedback loops and innovation (Koteshwar, 2017). We capture our contribution in three propositions, which can be used in further research.

\section{Literature}

2.1 Closed-loop supply chain management

A CLSC is a supply chain that integrates traditional forward supply chains with a reverse supply chain (Govindan et al., 2015). Formally, CLSC management is defined as "the design, 
control, and operation of a system to maximize value creation over the entire life cycle of a product with dynamic recovery of value from different types and volumes of returns over time" (Guide and Van Wassenhove, 2009). A conceptualization of CLSC flows and functions is depicted in Figure 1.

As shown in Figure 1, CLSC combines a forward supply chain with a reverse supply chain. The impetus for the reverse supply chain is a product return by customer. Importantly, CLSC are different from forward supply chains in many respects (Guide et al., 2003). The main difference between a forward supply chain and a reverse supply chain is that while the forward supply chain aims at producing and delivering products according to forecasted customer demand, the reverse supply chain deals with uncertain quantities of product returns of different qualities and thus needs to handle different returns in different ways (Rogers and Tibben-Lembke, 1999). A well-developed CLSC is economically and environmentally beneficial in the long term (Peng et al., 2020). From a value creation perspective, it is vital that forward and reverse chains are integrated into a CLSC as both have the potential to support each other (Schenkel et al., 2015). A CLSC is fundamentally a dynamic set of processes and routines having to meet the needs of changing market conditions (Abbey and Guide, 2017).

Recently, scholars have expanded CLSC research to strategic and long-term issues (Schenkel et al., 2015) and to interactions between forward and reverse supply chain networks (Fu et al., 2021). A key insight is that the CLSC value creation opportunities extend beyond direct, short-term economic value. Well managed information flows are an important part of circular value creation (Klapalova, 2019; Julianellia et al., 2020). Furthermore, a dynamic feedback loop, an essential part of a CLSC depicted in Figure 1, is one avenue for driving longterm CLSC value creation. The feedback loop is closely associated with organizational learning and innovation (Koteshwar, 2017), which in turn leads to improved decision making (Giri and Masanta, 2020). The feedback loop is enabled by the informational value embedded in CLSC and product returns (Schenkel et al., 2015; Ritola et al., 2020). The recognition of the potential of this information has given rise for the need for more research on CLSC-related IT, big data and information sharing (Guan et al., 2020). The importance of informational value stems from the fact that it provides market actors with necessary decision-making information, much like prices and sales figures. A customer always returns a product for a

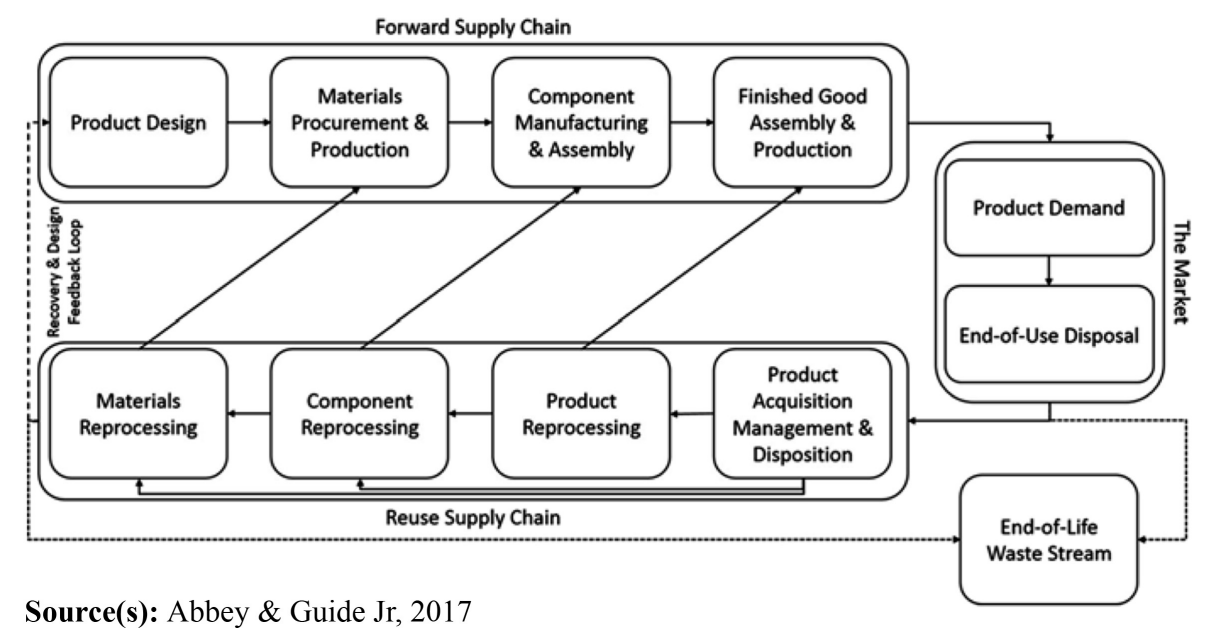

Learning-
based dynamic
capabilities
Figure 1.

Closed-loop supply chain flows and functions 
IJLM 33,5

specific reason, be it a commercial return, end of use return or end of life return. Understanding the reason for any given return is the primary source of the CLSC informational value (Ritola et al., 2020). If a firm can ascertain this reason, it can then use this information to adapt its processes, services and products accordingly. Because a returned product is always a specific product, bought at a specific time, through a specific channel, by a specific person and finally returned at a specific time in a specific way, it serves as a feedback loop for a variety of firms' activities. It is important to note that the value of this information goes beyond the initial product returns process. Therefore, much like the other value creation activities having to do with product returns, it is best to think of it as part of a CLSC (Schenkel et al., 2015).

More research is required on informational value and its impact on firm performance (Shekarian, 2020). Much of the existing literature has focused on IT factors of product return information (Ritola et al., 2020). However, IT alone is not enough to ensure a realized value creation. Instead, from a business value creation perspective, IT needs to be aligned with the overall business strategy (Walraven et al., 2018) and in as part of a complex business environment involving considerations of business agility (Johansson and Rusu, 2019), managerial issues such as organizational politics (Ritola et al., 2016). In order to consider this wider variety of factors, we undertake this study by putting CLSC value creation into a strategic management context via the use of the DC framework.

\subsection{Dynamic capabilities, organizational learning and microfoundations}

DC research aims to understand how firms can achieve and sustain competitive advantage by responding to dynamic market forces (Teece, 2007). From this perspective, firms achieve competitive advantage by adapting their resources and routines to fit the changing environment (Eisenhardt and Martin, 2000; Teece et al., 1997). DCs are defined as "the capacity of an organization to purposefully create, extend, or modify its resource base" (Helfat et al.,2007, p. 4). DCs consist of routines and entrepreneurial initiatives that continually enable a firm to create new resource configurations (Eisenhardt and Martin, 2000; Teece, 2016) and are systematic and planned in nature rather than ad hoc problem-solving (Winter, 2003).

Organizational learning plays at least three distinct roles in the DC framework. First, learning itself can be a DC. Second, other DCs are themselves learned. Finally, learning is the outcome of DCs (Schilke et al., 2018). This study focuses on the first kind: Learning as a DC. Organizational learning can be viewed as being formed by specific organizational routines (Levitt and March, 1988). Such learning routines have been shown to have the potential to serve as a dynamic learning capability when properly utilized (Salge and Vera, 2013). Following previous research in DCs and organizational learning literature, and especially Salge and Vera (2013), we identify three broad learning routines in the context of a CLSC. However, in this context, it is essential to distinguish between internal incremental learning, where learning primarily happens in internal firm routines, from CLSC learning routines where the external source of learning comes from the customer in the form of product returns. Therefore, learning becomes more complicated and difficult, but the insights become potentially more valuable. The main three routines are identified as problem detection, idea generation and adaptation. These correspond to the main routines, as identified by Salge and Vera (2013) and Teece (2007).

Furthermore, radical learning can be distinguished from incremental learning (Salge and Vera, 2013). Incremental learning can be viewed as the firm's ability to detect problems, generate ideas on addressing these problems and implementing solutions to remedy the issue (Salge and Vera, 2013). Whereas radical learning tends to change underlying organizational assumptions fundamentally, incremental learning steadily improves and refines the existing knowledge base of a firm, often based on practical challenges encountered (Salge and Vera, 2013). In this study, we focus on incremental, continuous learning and adaptation and its microfoundations. 
Microfoundations can be defined as "the distinct skills, processes, procedures, organizational structures, decision rules, and disciplines - which undergird enterprise-level sensing, seizing, and reconfiguring capacities" (Teece, 2007). Among other things, microfoundations research attempts to uncover the structural arrangements that underlie DCs (Felin and Foss, 2015). In this view, opportunity discovery can reside in organizational processes and routines (Teece, 2007). Hence, great importance in understanding the conditions and structures that enable and give rise to the DCs. This study focuses on a learning-based DC in the context of CLSC.

\section{Learning- based dynamic capabilities}

\section{Methodology}

For this study, we adopt a qualitative Delphi methodology. A Delphi study facilitates the exchange of expert knowledge and is suitable for exploratory studies concerning clarification of problems and opportunities as well as for solution development (Skulmoski et al., 2007; Hsu and Sandford, 2007). Delphi study is a flexible method, enabling interactive group communications (Hsu and Sandford, 2007) across different locations (Skulmoski et al., 2007) that can be either quantitative or qualitative, and data can be collected using multiple techniques (Skulmoski et al., 2007). Considering that this is an exploratory study aiming to increase knowledge on a complex, less-studied organizational issue, a Delphi study based on semi-structured one-on-one interviews is a suitable choice. Using interviews also increases information reliability, provides nuanced insights into a complex phenomenon and finally reduces participant dropout rate during the study. The same methodology has been successfully used in related research areas such as the circular economy (Tunn et al., 2019) and sustainable supply chain management (Seuring and Muller, 2008).

We adopted the following procedure. First, the initial interview questions for the study was developed from existing literature on CLSC value creation (Schenkel et al., 2015; Ritola et al., 2020), DCs (Teece et al., 1997) and organizational learning (Salge and Vera, 2013). Second, we assembled a panel of experts suitable to elaborate on and to contribute to the topic at hand. Next, the first round of interviews was conducted among the expert panel. The first round of interview questions revolved around the capabilities required for learning from product returns information and their microfoundations, the sources of valuable information and finally the use cases for the information. The questions were guided by previous literature on DC research (Salge and Vera, 2013) and CLSC information value research (Ritola et al., 2020). The results of the first interview round were used as a starting point for the second round of interviews, allowing the expert panel to elaborate and refine the framework, and to add comments. After the second round of interviews, the final conceptual framework along with a set of propositions was developed based on the interviews.

Following Skulmoski et al. (2007), we select the experts based on knowledge and experience on the topic, their capacity and willingness to participate, sufficient time for participation and excellent communication skills. Participants were chosen both from the academic community and from a practitioner field, with practitioners working in various industries. More specifically, business practitioners were chosen based upon their knowledge and experience related to CLSC management and product returns management or their expertise regarding organizational learning, knowledge management, innovation management and information systems management. The industry experts with expertise in CLSC have practical experience in CLSC management in the firms they worked in or consulted for and they come from different firms and different industry backgrounds. Other practitioners have expertise and experience in either IS, organizational learning, agility or strategy. Industries include consumer electronics, business to business electronics, telecommunications and networking, household items and fashion industries. Participants from the academic community were chosen based on their knowledge in CLSC management, 
IJLM 33,5

information systems management, organizational learning and knowledge management and strategic management. The aim was to allow experts to share their knowledge, experiences and expertise in a relevant way to the practical business problem as well as to theory development. The role of the academics was therefore to elaborate on the industry experts views, based on their theoretical knowledge along with their practical experience working with firms in CLSC management and organizational learning. Therefore, the interview process started with the interviews with the experts from the business community, followed by interviews with the academic experts. This allows academic experts of organizational learning to elaborate on the business problem as articulated by the practitioners close to the problems and opportunities.

Because of the newness of the practical business problem, i.e. combining $\mathrm{DC}$ with product returns management, suitable experts from the business community were hard to locate. Therefore, we used the snowballing technique to find more suitable experts by asking for new leads from the initial participants. The optimal size of the panel of experts ranges from 10 to 30 (Murry and Hammons, 1995). Seventeen participants were contacted based upon established contacts and the expertise of the potential participants. Finally, 10 experts participated in this study. Interviewee 2 had nothing to add to the results of the first round of interviews, and Interviewee 4 could not be reached for an interview, and thus, 10 interviewees participated on the first round of interviews and 8 interviewees participated on the second round of interviews. In total, 18 interviews were conducted for this study. The length of the interviews ranged from half an hour to one and half hour; most of the interviews being approximately one hour in length (see Table 1).

Thematic content analysis was used to analyze the data iteratively. The interview data were continuously analyzed, and after the first round of interviews, the preliminary framework was updated according to the expert panel feedback. The results of the first round were then presented to the expert panel for the second round of interviews. The interview data from the second round were analyzed the same way the first one, and the results of the second round form the final results of this study.

\section{Results}

Based on the interviews, both practitioners and academics, we formulate a conceptual framework on how continuous and incremental learning can serve as a DC leading to increased performance for firms. The views among the expert panel converged after two rounds of interviews and a consensus was reached. No major divergencies were detected in the views of the academics as compared to the practitioners. The framework consists of the sources of product returns information, the capabilities required for continuous learning along with their microfoundations and finally, the business value that can be derived from the information. The participants agreed that ultimately continuous learning from product returns information leads to increased firm performance. Interviewee 1 considers the returns process an extension of the relationship between a firm and the customer: "the returns process gives an opportunity to better engage with your customer over time and I think you can learn a few things." The conceptual model for incremental learning from product returns information is depicted in Figure 2.

The results indicate that product returns information can be a valuable source for value creation for firms. Interviewee 1 sums it up thusly: "having returns is a blessing, because it gives you so much insight into the future". All the study participants agree upon the high potential value of the information although many participants added that much of it remains unused in practice. The reasons for this neglect were mentioned by the panel as lack of relevant knowledge, overemphasis on short-term profit and sales and the general tendency for firms to treat RL as an afterthought or a necessary evil rather than a value creation 


\begin{tabular}{|c|c|c|c|c|}
\hline & & $\begin{array}{l}\text { Expertise and } \\
\text { Experience }\end{array}$ & Industry & $\begin{array}{l}\text { Learning- } \\
\text { based dynamic }\end{array}$ \\
\hline Interviewee 1 & Practitioner & CLSC, IS & Consulting in many industries & \\
\hline Interviewee 2 & Practitioner & CLSC & B2B Electronics & \\
\hline Interviewee 3 & Practitioner & CLSC & $\begin{array}{l}\text { B2B Electronics, Service Business } \\
\text { model }\end{array}$ & \\
\hline Interviewee 4 & Practitioner & CLSC, Learning & Electronics & 75 \\
\hline Interviewee 5 & Practitioner & Agility, Learning & Consulting in many industries & \\
\hline Interviewee 6 & Practitioner & Strategy, IS & Consulting in many industries & \\
\hline Interviewee 7 & Practitioner & IS, Learning & Consulting in many industries & \\
\hline Interviewee 8 & Practitioner & CLSC, Learning & Household Items & \\
\hline Interviewee 9 & Academic & CLSC, Learning, IS & Fashion & Table 1. \\
\hline Interviewee 10 & $\begin{array}{l}\text { Academic, } \\
\text { Practitioner }\end{array}$ & $\begin{array}{l}\text { CLSC, Strategy, } \\
\text { Learning }\end{array}$ & Telecommunications and Networking & $\begin{array}{l}\text { Overview of the } \\
\text { participants }\end{array}$ \\
\hline
\end{tabular}

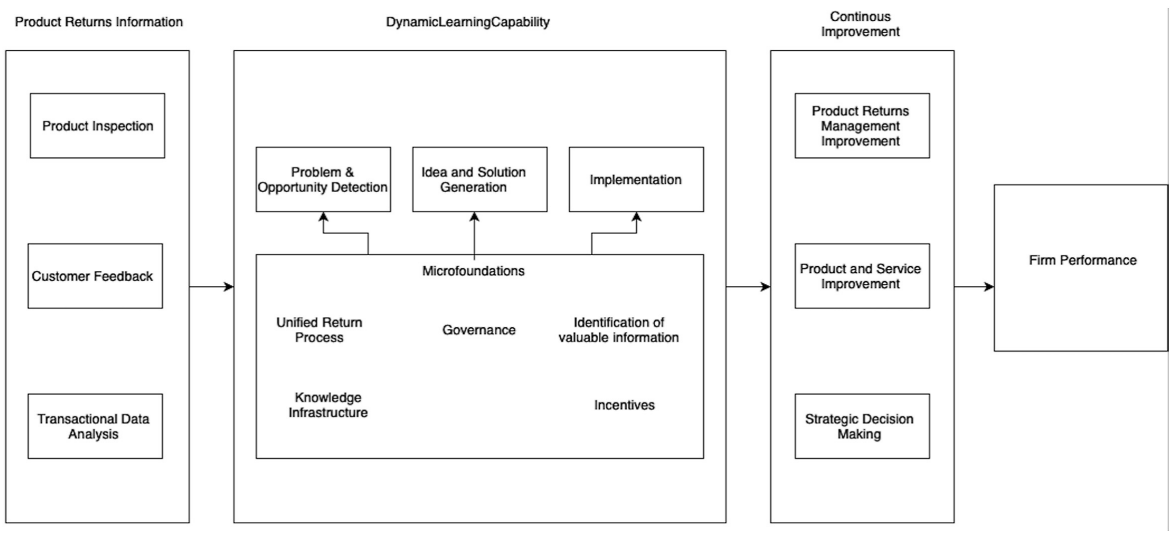

Figure 2. Incremental learning from product returns information conceptual model

opportunity. For instance, Interviewee 8 said: "It's about short term thinking. These kinds of things take time to pay off, but if you only think short term then you will never make the commitment that profits you even more long term". Nevertheless, each panelist identified productive uses of returns information along with conditions and prerequisites for successfully creating long term value. Each participant, moreover, agreed on the high value of product returns information.

However, the results indicate that not all of the information is particularly valuable in all situations. For instance, certain kinds of information can be acquired more efficiently through other means, such as remote monitoring of the product's usage. Interviewee 2 emphasizes that in some cases the product return is not required: "answer would be that you do not need to return the product. What you want to do is to monitor the products remotely." Furthermore, some of the information can be more valuable in other industries, and at other times, the investments required to make the most of the information might not be of great value for a given firm. Moreover, product returns information is hard to utilize. Hence, product returns information is no silver bullet. Instead, the necessary capabilities should only be built if and when the information fits the firm's overall business strategy and when the same information is not available and accessible with less effort and investments required. 
IJLM 33,5

\subsection{Sources of information}

The expert panel agreed on three sources of valuable information. These are customer feedback, product inspection and transactional data analysis. In practice, valuable information comes from one or more sources. In most cases, it is beneficial to have more than a source to be sure of the insight. For instance, a customer might give a reason for the return that the product is faulty in a certain way. In such cases, the product should be inspected to confirm the reason and to get more insights into the product failure.

The first source of customer feedback consists of the feedback given by the customer as part of the return process. This can be either structured data in the form of a survey or unstructured data as part of an open-ended question on a survey or qualitative data in the form of a discussion with a customer service person. The experts emphasized usefulness and value of the survey data. While hard to validate, in some cases, it can be validated through the other sources, for instance, by comparing the return reason given by the customer with inspection of the returned product in order to make sure the information matches. The usefulness of the qualitative data was, on the one hand, said to be low as none of the experts had witnessed a systematic, effective use of in practice. However, most of them speculated that it probably has a high value if codified and used properly.

Inspection of the returned product is another source of information. Interviewee 1 points out that "when a customer has returned a product and when products are being received and graded in warehouses, you can learn awful lot from the products". This involves having a system in place where every returned product is inspected and observations recorded systematically. Understanding the reason for product failure is of great importance. Interviewee 2 says that "once you understand why it failed, then you communicate. You might need to communicate to design or you might need to communicate to purchasing or manufacturing. But to know you need data and information. So, depending on the reasons for why that item is coming back, there are certain decisions you need to make."

Analysis of returns transactional data was identified as the third source of information by the expert panel. Interviewee 10 illustrates the value of these data as follows. "For instance, if you have a customer who returns $30 \%$ of all orders then there's a reason for that and you can try to understand that reason. But first it's important to understand these patterns, first it's important to know that this customer has $30 \%$ of returns." In order for firms to draw valuable insights from this these patterns, the necessary data from returns transactions need to be identified, collected and then integrated into the overall data storage of the. Interviewee 1 mentions that "if you can combine the order data and the return data, you can not only learn from about their shopping preferences, but you can also much further deep dive into the return behavior." Interviewee 7 points that "the more data you have the better, and returns process is no exception but you must know how to use it".

\subsection{The value of information}

The value of the product returns information comes from its potential to serve as a continuous source of learning and improvement. Interviewee 10 mentions every return is a potential for improvement because "when you have returns, this is always a sign of lack of quality." The experts elaborated on how it can be used for these purposes by identifying three broad categories of improvement. Product returns management improvement, product and servicerelated improvements, and lastly, strategic improvements. Interviewee 1 emphasizes both the high value and the underutilized nature of this information. "Interviewee 1: "Back to your question should companies incorporate the decisions strategically. Absolutely. Does it happen? Yes. Does it happen a lot? No. But of course they should”.

Product returns management improvement involves the improvement regarding the return process, the return policy and logistics. Interviewee 1 discusses some areas for improvement 
"there are three main areas for improvements: Cycle time (speed), cost, and recovery of products." Customer satisfaction regarding the return process and policy can be tracked and improved. Return policy can be optimized using real-time data and individualized return policy. For instance, in the case of a frequent, fraudulent returner, a firm can set a different return policy, in real time, to that particular customer specifically. Moreover, a firm can attempt to reduce returns, having identified segments of customers who frequently return. Additionally, problems and inefficiencies along the return process can be identified and improved. For example, packing materials, when they fail, can be identified and improved. Another improvement has to do with decision regarding the scope of the return. That is should a whole product be returned or for instance only a broken part. Interviewee 10 discusses this issue in the following way. "Do we have our returns on the right level. There are examples where the whole unit is sent back because of a broken cable. You have to think about what criteria is the spare part based on. This is a continuous thinking about do we have the returns on the right level[ ...]. Based on this you can get a lot of feedback for the product development. For instance, changing a fuser, the fuser should be in a place that it can be easily replaced."

Products and services can be continuously improved based on returns information. This refers to information coming directly from failure diagnostics which can improve parts of products or create a new product. One interviewee emphasizes the need to understand the root causes of a failure: "To understand the design failure and analysis and disciplines regarding what is actually happening. What are the actual root causes of the issues you see in the equipment”. Moreover, information can lead to improvements throughout the supply chain. For instance, packing material improvement in case products is returned because of damage during transportation. Furthermore, products can be returned due to the wrong product ordered caused by confusing ordering processes, and sometimes products are returned due to a misleading picture or description on a website. Such errors can be identified from returns.

Strategic customer-related factors were considered important by the experts. This category has to do with changing customer needs and wants and understanding customer behavior. This is also the hardest to utilize as pointed out by Interviewee 2: "Very few are collecting this information. It all starts to understanding your install base. And a lot of people do not know where the machines are and they do not know their install base. Once you understand your install base, then you need to understand the customer". This means, for instance, understanding why a customer returns an item when they are planning to replace it with a new, perhaps an improved version or a similar item. By understanding the missing features of the current product, product designers can understand customer needs better and thus make products that match the customer needs better. For example, a customer in a specific location might have differing needs form other customers as illustrated by Interviewee 10: "For instance we had some customers who were from a country where the air was not so clean and the customer was not so aware of how to keep the equipment clean and dust free." In this case, this insight was used in order to improve the product but also to educate customer on how to better extend the life of the product.

\subsection{Learning capabilities and microfoundations}

The experts unanimously agreed with respect to the three high-level capabilities required for learning from returns. This is in line with prior research. The results indicate that these capabilities manifest in three stages: (1) problem and opportunity detection, a stage where problems or opportunities regarding the product, services, returns management and strategy are identified; (2) idea generation, a stage where solutions and new ideas are formulated based upon the opportunities and problems detected; and lastly (3), the implementation of the chosen solution. A majority of the experts were interested in discussing the microfoundations. Additionally, the experts were concerned about the difficulty of implementing solutions or as Interviewee 1 put it: "The big problem is to drive again 
IJLM 33,5 change to make improvements." The following microfoundations were identified: Identifying relevant and valuable information, governing of learning, a unified return process, a knowledge infrastructure and setting proper incentive structures.

Experts emphasized that while they could see the potential value of all the kinds of information identified, not all of it was valuable for every firm and under all circumstances. Therefore, a firm needs to identify the relevant type of information that is valuable for their specific business needs. The results indicate that the specifics depend on the industry, business model and currently available information. The value of a certain type of information is also dependent on the type of returns the firm mostly deals with. For instance, commercial returns would be less valuable regarding how to improve product reliability, because the end-of-life returns give much more insight regarding reasons for product failure as compared to commercial returns. Additionally, during the return process, firm needs to know what questions to ask the customer in order to collect the right data. Similarly, the type of data collected from product inspection should be specified, and the types of transactional data collected should defined and structured. This data specification process can, for example, involve information regarding condition, specific reason of failure and the specific part and module that failed. For instance, Interviewee 1 stated: "of course when a customer has returned a product and when products are being received and graded in warehouses, you can learn awful lot from the products. And you can validate the consumer behavior. You can validate what the customer told you during the return process versus the what do we see when we open the box. If customers tell you that they return clothing that are unused, but the grading process at the warehouse tells you that they have been used, there's a deviation and the deviation if first of all used to calculate the final refund to the customer but second you can also, with big data, learn how much consumers create misperception by giving you wrong information at the beginning of the process, versus the validation downstream."

The interviewees emphasized the need for a unified product returns process. The lack of a cohesive and unified returns process is one of the largest obstacles for continuous learning from product returns. Interviewee 1 says: "I'm a very firm believer in saying that creating data can only happen if you have a robust process. Unified and preferably running in one system." When the returns process is not designed as a cohesive whole, the return process remains fragmentary, and the information associated with it is siloed. A unified returns process is particularly significant in the context of product returns information as the potential value of the information is wider ranging than in the context of returns and thus requires more stakeholders and decision makers to capitalize on it. More stakeholders also make utilizing returns information more complex and difficult. Interviewee 1 says: "they do not have the data because they have not unified their returns process. There's a little bit of data here, there's a little bit of data there, and there's a little bit of data there. If you do not unify and bring that data together, you do not have data let alone that you can do analysis." Moreover, lack information integration between reverse logistics and forward logistics is another barrier learning from product returns information. Hence, the different CLSC activities need to be integrated in order to make learning effective. Interviewee 1 says in this respect: "This includes having all the information, from all sections of the CLSC, in one place accessible and tied to a same customer profile. Product returns related information also needs to be integrated with forward supply chain information, and returns transaction data needs to be traceable back to the original purchase and purchaser.”

The creation of a knowledge infrastructure was deemed important by the experts. Creating a knowledge infrastructure involves setting up the necessary databases, data collection methods, defining the data requirements, integration of the data into current systems used by the firm. Interviewee 1 points out the lack of data collection as part of returns process: "Many companies do not have online retail authorization process. Which means that the data, the customer data who's my customer where are they located, what did they buy, 
what do I return and why, that data is not registered". Likewise, Interviewee 4 underscores the need for IT systems: "There were IT systems that supported it. That's important. The parts were identified, they were scanned, they had a code, they were stocked in certain way that you could see what was what." Interviewee 6 mentions that: "you simply have to have the IT in place and if you do not have IT that supports the return process then you need to create it or buy it". Interviewee 2 says that there is also a problem with being disciplined in the use of the IT: "It's because of lack of discipline [. . . ] lot of times. People are not entering the right data. Could be because of mistakes when entering that data. Could be because systems are not connected. It can be because nobody really cares about the problems once they are solved. There are lot of reasons. That's why that information is not available". However, many experts noted that data requirements are not often the main bottleneck in organizational learning. This is the case because the data needs to be spread among the necessary stakeholders and needs to be made understandable for them to make it possible that they can draw insights from it. This involves codification, visualization of knowledge, cross-functional teams with knowledge sharing. Interviewee 4 illustrates the point: "You need the support of people in their daily behaviors. That depends on who was in charge and who was working with it. We had a very severe human relations management. So, people got a lot of introductions, a lot of possibilities to look at other departments and work together. By doing so it was supported that people really collaborated. They visited each other; they had the time to learn from each other". Interviewee 7 points out that: "it's not enough to have the data, but you have to be able to visualize it for the decision makers who are not data scientists". Ultimately, the knowledge infrastructure is there to make sure that "that the information they are getting will end up in the table of the right people" as Interviewee 2 puts it.

Due to the complexity of the learning process and necessary stakeholders involved to make it work, it is important that top management is part of the planning and coordination of learning from returns. Interviewee 10 states bluntly: "Without top management involvement nothing happens."

Top management involvement means that a necessary learning governance structure should be put in place, which involves allocating decision rights and responsibilities to ensure cooperation. For instance, logging in necessary information, analyzing it, generating ideas, implementation should all be assigned to a specific person or a team. Additionally, the success of the learning routines should be measured. However, some participants hesitated regarding strict measurements, emphasizing that it might be difficult, or even counterproductive in some instances because innovation routines can be hard to measure. It may be beneficial for certain firms to engage in discovery-based learning, where the goal of the learning is not predetermined but may emerge from the new insights gained.

One of the largest challenges of developing a dynamic learning capability based on product returns information is the complexity and number of stakeholders involved, all of whom have various, differing incentives. Interviewee 4 says: "So, there you can see the tension between sales and research and development because at a certain moment they want to have a new release and they can't wait for the new development and they will just skip it." The rewards from the learning outcomes might take long time in some cases. Participants identified short-term thinking as a significant barrier from learning from returns along with the solution of rethinking incentives to orient managers for longer term thinking. Interviewee 2 says: "Obviously, that would be the incentives issue. Yes, purchasing might incentivized by cost cutting. Marketing might be incentivized by PR, getting the valuable proposition out. Sales might be incentivized by margins instead of volumes or value. That will create conflict and I have experienced this myself." Additionally, the key stakeholders (different firms on the supply chain, different departments/managers inside one firm) need to have shared incentives for learning from returns to aid cooperation. 
IJLM 33,5

80

\section{Conclusion, discussion and limitations \\ 5.1 Conclusion}

In order to explore the multifaceted value creation potential of CLSC informational value, we conducted a qualitative Delphi study among 10 experts from the industry and academia. The study started with an initial framework derived from extant literature, after which it was refined via two rounds of interviews among the experts. Using interviews in connection with the Delphi method led to rich insights regarding this relatively novel topic. A conceptual framework for continuous learning from product returns information was developed, along with its microfoundations.

This study contributes to the growing literature on CLSC value creation by exploring the potential of continuously learning from CLSC informational value stemming from product returns. Based on the expert panel interviews, it is clear that CLSC informational value is a valuable source of feedback regarding the CLSC. However, many practical challenges remain for firms. Firms are not capable of fully utilizing information from product returns. We identify the sources of valuable information, the value that can be derived from the information along with the necessary capabilities and their microfoundations. The developed framework allows firms to start developing necessary capabilities for continuous learning on one hand and the researchers to start building upon this foundation with further research. It should be noted that it may not always be beneficial for a firm to devote resources to building up the necessary capabilities, for instance when the value of information remains low or when the information is available through more convenient channels. Still, in many cases, the opportunity is too large to be missed.

\subsection{Discussion}

This study built on the recent efforts to increase scholarly understanding regarding CLSC value creation (Ritola et al., 2020; Schenkel et al., 2015; Koppius et al., 2014) and knowledge value chain (Gaimon and Ramachandran, 2020). More specifically, we aimed to advance insights into the potential of product returns information (Jayaraman and Luo, 2007; MihiRamirez, 2012), by applying the DCs view into a new functional domain, namely CLSC management. We suggested that product returns information should be thought of as a source for increased value creation, as much of the extant literature has emphasized the value of the information in terms of its ability to increase product returns management performance (Ritola et al., 2020). The results of this study confirm that the high value of improving product returns management goes beyond that. For instance, the expert panel agreed that the value of product returns information goes beyond returns management - to product and service improvement areas and strategic decision-making through a better understanding of customer needs. The results of this study supplement the existing CLSC value creation research-based theories such as resource-based view (Jayaraman and Luo, 2007) and stakeholder theory (Schenkel et al., 2019).

Furthermore, our results indicate that informational value is a valuable source of information that can be used to systematically and continuously improve several aspects of a CLSC. Continuous incremental learning is based on the information coming from customer feedback, an inspection of the returned products and transactional data analysis. It has the potential to increase firm performance and lead to a competitive advantage under certain conditions. Thus, we conclude that continuously learning and adapting the CLSC based on the product returns information can be considered a DC. The most novel contribution of this study is the set of microfoundations identified, namely, unified return process, governance, identification of relevant valuable information, knowledge infrastructure and setting incentives. 
In terms of practice, our study informs managers regarding the sources of valuable information in a CLSC, its use business cases, capabilities required to create value from it and lastly, the managerial considerations that should be taken into account when implementing projects and systems related to maximizing CLSC value creation from the available information. However, it is important to note some of the limitations that learning from product returns information entails. It may be easier and more efficient in some cases to capture similar information via other means, for instance through remote monitoring through sensors. Another limiting factor may concern privacy issues. While undoubtedly very valuable, some of the analyses may be limited by privacy related laws.

Based upon the discussion of the results of this study and the conceptual framework developed, we put forth the following three propositions.

Proposition 1. Dynamic learning capabilities lead to continuous improvement of product returns management, products and services and strategic decisionmaking, and ultimately to increased firm performance.

The results of this exploratory study indicate that the learning capabilities do lead to increased performance as shown in Figure 2. This is in line and supported by the DC theory. However, CLSC research on this topic is lacking. Therefore, more quantitative research is required to validate this finding. Moreover, much of existing CLSC is operational rather than strategic. Therefore, further studies along the lines of this proposition help to fill the gap in strategic CLSC management research.

Proposition 2. The microfoundations (unified return process, governance, identification of valuable information, knowledge infrastructure and incentives) underlie the three dynamic learning capabilities.

Future research should both validate the set of microfoundations identified as depicted in Figure 2. More research is required in order to ensure that the microfoundations include each necessary one and that each of them is required to build learning capabilities in a CLSC. While the expert participant of this study could not identify any additional microfoundations, it is entirely possible case studies and other exploratory studies might uncover additional ones.

Proposition 3. The findings indicate that customer feedback is most useful for improving customer satisfaction, product returns for improving product and process design and transactional data for analyzing ordering and returns behavior.

In future research, it can be detailed which type of returns information is useful for which type of value creation and performance improvement. This research indicates that certain types of information sources or most valuable for certain types of improvements. More research is required to validate this finding.

\subsection{Limitations}

This study has several limitations. The sample consisted of a limited number of experts. Although this study covered two interview rounds and engendered in-depth discussions with well-informed experts, future studies may extend our results with additional insights. While our experts come from various industries, case studies in different industries and differing product returns environments could be conducted to ensure the robustness of this framework. Moreover, due to the methodology of this study, it was not possible to investigate the phenomenon in depth at firm level or at supply chain level. Therefore, further theory testing case studies on the proposed framework are required both on a firm level and on the level of the supply chain. 
IJLM 33,5

82

\section{References}

Abbey, J.D. and Guide, V.D.R. Jr (2017), “Closed-loop supply chains: a strategic overview”, Sustainable Supply Chains, Springer, Cham.

Beske, P. (2012), "Dynamic capabilities and sustainable supply chain management", International Journal of Physical Distribution and Logistics Management, Vol. 42 No. 4, pp. 372-387.

Beske, P., Land, A. and Seuring, S. (2014), International Journal of Production Economics, Vol. 152, pp. 131-143.

Blome, C., Schoenherr, T. and Rexhausen, D. (2013), "Antecedents and enablers of supply chain agility and its effect on performance: a dynamic capabilities perspective", International Journal of Production Research, Vol. 51 No. 4, pp. 1295-1318.

Daugherty, P.J., Myers, M.B. and Richey, G.R. (2002), "Information support for reverse logistics: the influence of relationship commitment”, Journal of Business Logistics, Vol. 23 No. 1, pp. 85-106.

Daugherty, P.J., Richey, G.R., Genchev, S.E. and Chen, H. (2005), "Reverse logistics: superior performance through focused resource commitments to information technology", Transportation Research Part E, Vol. 41 No. 2, pp. 77-92.

Eisenhardt, K.M. and Martin, J.A. (2000), "Dynamic capabilities: what are they?", Strategic Management Journal, Vol. 10 No. 11, pp. 1105-1121.

Felin, T. and Foss, N.J. (2015), "The microfoundations movement in strategy and organization theory", The Academy of Management Annals, Vol. 9 No. 1, pp. 575-632.

Fu, R., Qiang, Q., Ke, K. and Huang, Z. (2021), "Closed-loop supply chain network with interaction of forward and reverse logistics", Sustainable Production and Consumption, Vol. 27, pp. 737-752.

Fundin, A.P. and Bergman, B.L. (2003), "Exploring the customer feedback process", Measuring Business Excellence, Vol. 7 No. 2, pp. 55-65.

Fundin, A. and Elg, M. (2010), "Continuous learning using dissatisfaction feedback in new product development contexts", International Journal of Quality and Reliability Management, Vol. 27 No. 8, pp. 860-877.

Gaimon, C. and Ramachandran, K. (2020), "The knowledge value chain: an operational perspective", Production and Operations Management, Vol. 30 No. 2, pp. 715-724.

Giri, B. and Masanta, M. (2020), "Developing a closed-loop supply chain model with price and quality dependent demand and learning in production in a stochastic environment", International Journal of Systems Science: Operations and Logistics, Vol. 7 No. 2, pp. 147-163.

Govindan, K., Soleimani, H. and Kannan, D. (2015), "Reverse logistics and closed-loop supply chain: a comprehensive reviewto explore the future", European Journal of Operational Research, Vol. 240, pp. 603-626.

Guan, G., Jiang, G., Gong, Z., Huang, Y. and Jamalnia, A. (2020), “A bibliometric review of two decades research on closed-loop supply chain: 2001-2020”, IEEE Access, Vol. 9, pp. 3679-3695.

Guide, V.D.R. Jr and Van Wassenhove, L.N. (2009), "The evolution of closed-loop supply chain research”, Operations Research, Vol. 57 No. 1, pp. 363-375.

Heese, H.S., Cattani, K., Ferrer, G., Gilland, W. and Roth, A.V. (2005), “Competitive advantage through take-back of used products", European Journal of Operational Research, Vol. 164 No. 143, p. 157.

Helfat, C., Finkelstein, S., Mitchell, W., Peteraf, M., Singh, H., Teece, D. and Winter, S.G. (2007), Dynamic Capabilities: Understanding Strategic Change in Organizations, Blackwell, Malden (in press).

Hsu, C.-C. and Sandford, B.A. (2007), "The Delphi technique: making sense of consensus”, Practical Assessment, Research and Evaluation, Vol. 12 No. 10, pp. 1-9.

Jayaraman, V. and Luo, Y. (2007), "Creating competitive advantages through new value creation: a reverse logistics perspective", Academy of Management Perspectives, Vol. 21 No. 2, pp. 56-73. 
Johansson, F. and Rusu, L. (2019), "Barriers to agility in a large company's IT organization", International Journal of Innovation in the Digital Economy, Vol. 10 No. 1, pp. 1-17.

Julianellia, V., Caiado, R.G.G., Scavarda, L.F. and Cruz, S.P.d. M.F. (2020), "Interplay between reverse logistics and circular economy: critical success factors-based taxonomy and framework", Resources, Conservation and Recycling, Vol. 158.

Klapalova, A. (2019), "Customer product returns - feedback and knowledge management", Measuring Business Excellence, Vol. 23 No. 2, pp. 149-164.

Koppius, O., Özdemir-Akyıldırım, Ö. and van der Laan, E. (2014), "Business value from closed-loop supply chains", International Journal of Supply Chain Management, Vol. 3 No. 4, pp. 107-120.

Koteshwar, C. (2017), Clarifying the Feedback Loop Concept for Innovation Capability: A Literature Review, ISPIM, VIenna.

Krikke, H., Hofenk, D. and Wang, Y. (2013), "Revealing an invisible giant: a comprehensive survey into return practices within original (closed-loop) supply chains", Resources, Conservation and Recycling, Vol. 73, pp. 239-250.

Levitt, B. and March, J.G. (1988), "Organizational learning”, Annual Review of Sociology, Vol. 14, pp. 319-340.

Mahringer, C.A. and Renzl, B. (2018), "Entrepreneurial initiatives as a microfoundation of dynamic capabilities", Journal of Accounting and Organziational Change, Vol. 14 No. 1, pp. 61-79.

Martin, P., Guide, V.D.R. Jr and Craighead, C.W. (2010), "Supply chain sourcing in remanufacturing operations: an empirical investigation of remake versus buy", Decision Sciences, Vol. 41 No. 2, pp. 301-324.

Mihi-Ramirez, A. (2012), "Product return and logistics knowledge: influence on performance of the firm”, Transportation Research Part E, Vol. 48 No. 6, pp. 1137-1151.

Mihi-Ramírez, A. and Morales, V.J.G. (2011), "Improving competitiveness trough creation of knowledge and reverse logistics", Inzinerine Ekonomika-Engineering Economics, Vol. 22 No. 4, pp. 443-450.

Murry, J.W. Jr and Hammons, J.O. (1995), "Delphi: a versatile methodology for conducting qualitative research", The Review of Higher Education, Vol. 18 No. 4, pp. 423-436.

Ritola, I., Siugzda, R. and Rusu, L. (2016), "The influence of organizational politics on business-IT alignment", International Journal of IT/Business Alignment and Governance, Vol. 7 No. 1, pp. 33-48.

Peng, H., Shen, N., Liao, H., Xue, H. and Wang, Q. (2020), "Uncertainty factors, methods, and solutions of closed-loop supply chain - a review for current situation and future prospects", Journal of Cleaner Production, Vol. 254 No. 1.

Ritola, I., Krikke, H. and Caniëls, M.C. (2020), "Learning from returned products in a closed loop supply chain: a systematic literature review", Logistics, Vol. 4 No. 7, pp. 1-13.

Rogers, D.S. and Tibben-Lembke, R.S. (1999), Going Backwards: Reverse Logistics Trends and Practices, Center for Logistics Management, Reverse Logistics Executive council, Reno (University of Nevada).

Röllecke, F.J., Huchzermeier, A. and Schröder, D. (2018), "Returning customers: the hidden strategic opportunity of returns management", California Management Review, Vol. 60 No. 2, pp. 176-203.

Rosenberg, N. (1982), Inside the Black Box: Technology and Economics, Cambridge University Press, Cambridge.

Salge, T.O. and Vera, A. (2013), "Small steps that matter: incremental learning , slack resources and organizational performance", British Journal of Management, Vol. 24, pp. 156-173.

Schenkel, M., Caniëls, M.C., Krikke, H. and van der Laan, E. (2015), "Understanding value creation in closed loop supply chains - past findings and future directions", Journal of Manufacturing Systems, Vol. 37, pp. 729-745. 
IJLM 33,5

\section{4}

Schenkel, M., Krikke, H., Caniëls, M.C. and Lambrechts, W. (2019), "Vicious cycles that hinder value creation in closed loop supply chains: experiences from the field", Journal of Cleaner Production, No. 223, pp. 278-288.

Schilke, O., Hu, S. and Helfat, C.E. (2018), "Quo vadis, dynamic capabilities? A content-analytic review of the current state of knowledge and recommendations for future research", Academy of Management Annals, Vol. 12 No. 1, pp. 390-439.

Seuring, S. and Muller, M. (2008), "Core issues in sustainable supply chain management - a Delphi study", Business Strategy and the Environment, Vol. 17 No. 8, pp. 455-466.

Shekarian, E. (2020), "A review of factors affecting closed-loop supply chain models", Journal of Cleaner Production, Vol. 253.

Skulmoski, G.J., Hartman, F.T. and Krahn, J. (2007), "The Delphi method for graduate research", Journal of Information Technology Education, Vol. 6, pp. 1-21.

Teece, D.J. (2007), "Explicating dynamic capabilities: the nature and microfoundations of (sustainable) enterprise performance", Strategic Management Journal, Vol. 28, pp. 1319-1350.

Teece, D.J. (2016), "Dynamic capabilities and entrepreneurial management in large organizations: toward a theory of the (entrepreneurial) firm”, European Economic Review, Vol. 86, pp. 202-216.

Teece, D.J., Pisano, G. and Shuen, A. (1997), "Dynamic capabilities and strategic management", Strategic Management Journal, Vol. 18 No. 7, pp. 509-533.

Tunn, V.S., Bocken, N.M., van den Hende, E.A. and Schoormans, J.P. (2019), "Business models for sustainable consumption in the circular economy: an expert study", Journal of Cleaner Production, Vol. 212, p. 324e333.

Walraven, P., van de Wetering, R., Helms, R., Versendaal, J. and Caniëls, M. (2018), "Co-evolutionary IS-alignment: a complex adaptive systems perspective", in The 12th Mediterranean Conference on Information Systems, p. 27.

Winter, S.G. (2003), "Understanding dynamic capabilities”, Strategic Management Journal, Vol. 24 No. 10, pp. 991-995.

\section{Further reading}

Guide, V.D.R. Jr and Van Wassenhove, L.N. (2003), "The challenge of closed-loop supply chains", INFORMS Journal of Applied Analytics, Vol. 33 No. 6, pp. 1-6.

Guide, V.D.R., Jayaramanb, V. and Linton, J.D. (2003), "Building contingency planning for closed-loop supply chains with product recovery V", Journal of Operations Management, Vol. 21, pp. $259-279$.

\section{Corresponding author}

Ilkka Ritola can be contacted at: ilkka.ritola@ou.nl

For instructions on how to order reprints of this article, please visit our website:

www.emeraldgrouppublishing.com/licensing/reprints.htm

Or contact us for further details: permissions@emeraldinsight.com 